\title{
infância, alteridade e formação docente: encontro com as crianças como potência de transformação
}

\author{
tiago ribeiro ${ }^{1}$ \\ instituto nacional de educação de surdos, brasil \\ universidade federal do estado do rio de janeiro, brasil \\ rafael de souza ${ }^{2}$ \\ universidade federal do estado do rio de janeiro, brasil \\ adrianne ogêda guedes ${ }^{3}$ \\ universidade federal do estado do rio de janeiro, brasil
}

resumo

O presente trabalho busca compartilhar reflexões produzidas no bojo de uma ação investigativa desenvolvida no cotidiano de uma escola pública localizada na cidade do Rio de Janeiro, com o objetivo de pensar o processo de formação docente e a potencialidade da criança nele. Por meio de uma investigação na perspectiva da pesquisa com o cotidiano, lançando mão de narrativas produzidas no caderno de campo e de impressões e sentidos criados ao longo da investigação, traz duas cenas vivenciadas no dia a dia da escola citada e, com elas, discute concepções de formação e de criança, defendendo esta última como um outro legítimo na formação do professor e a formação como um processo singular e, ao mesmo tempo, coletivo e polifônico. Finalmente, a partir da problematização proposta, o texto convida a pensar a formação com a infância na qualidade de uma formação como experiência: aquela que dá a pensar e a pensar-se, ou seja, uma formação que nos desloca e provoca a indagar nossas certezas e verdades cristalizadas, nos invita a ser já outros de nós mesmos, a repensar nossos modos de ser, estar e viver a docência com as crianças. Portanto, trata-se de um convite a que possamos pensar nosso lugar e o lugar das crianças, em outras palavras, nossa relação no educativo e na formação.

palavras-chave: formação docente; infância; alteridade.

\section{childhood, alterity and teacher training: meeting with children as a powerful transformation}

abstract

This paper aims to share reflections produced in the core of a research developed in everyday life of a school located in the city of Rio de Janeiro, in order to think the teacher training process and the child's potentiality in it. Through an investigation from the perspective of research with daily life, making use of narratives produced in the field notebook and of impressions and senses created throughout the investigation, brings two scenes experienced in the daily life of the mentioned public school and, with them, discusses concepts of training and child, defending the latter as a legitimate other in teacher education and training as a singular process and at the same time, collective and polyphonic. Finally, from the proposed problematization, the text invites us to think training with childhood in the quality of training as experience: that one which makes us think and think about ourselves, that is a training that moves us and causes us to inquire

\footnotetext{
${ }^{1}$ E-mail: tribeiro.ines@gmail.com

2 E-mail: desouza.rafaelf@gmail.com

${ }^{3}$ E-mail: adrianne.ogeda@gmail.com
} 
about our certainties and crystallized truths, invites us to be already others of ourselves, to rethink our ways of being, to be and to live the teaching experience with the children. Therefore, it is an invitation to think about our place and the place of children, in other words, our relationship in education and teacher's training.

keywords: teacher training; childhood; otherness.

\section{infancia, alteridad y formación docente: encuentro con los niños como potencia de transformación}

resumen

Este texto busca compartir reflexiones producidas en el seno de una investigación desarrollada en el cotidiano escolar de una escuela pública ubicada en la ciudad de Rio de Janeiro, con el objetivo de pensar el proceso formativo docente y la potencialidad del niño en él. A través de una investigación en la perspectiva de la investigación con el cotidiano y del trabajo con narrativas producidas en el cuaderno de campo, el artículo trae dos escenas vivenciadas en el día a día de una escuela pública carioca y, con ellas, discute concepciones de formación y de niño, defendiendo este último como un otro legítimo en la formación de maestros y la formación como un proceso singular y, al mismo tiempo, colectivo y polifónico. Finalmente, desde la problematización propuesta, invita a pensar la formación con la infancia en la calidad de una formación como experiencia: aquella que da a pensar y a pensarse, es decir, una formación que nos desplaza y provoca indagar nuestras certezas y verdades cristalizadas, que nos invita a ser ya otros de nosotros mismos, a repensar nuestros modos de ser, estar y vivir la docencia con los niños. Por lo tanto, se trata de una invitación para que podamos pensar nuestro lugar y el lugar de los niños, en otras palabras, nuestra relación en el educativo y en la formación.

palabras clave: formación docente; infancia; alteridad. 
infância, alteridade e formação docente: encontro com as crianças como potência de transformação

As crianças sabem jogar e brincar, enquanto os adultos, sérios, perderam a capacidade de ser mágicos e de fazerem milagres. (Selvino Assmann)

\section{introdução}

São inúmeras as ações e movimentos instituintes no campo da formação docente, os quais buscam construir processos formativos de professores de modo colaborativo e democrático, apostando na partilha entre os pares, na circulação da palavra e na valorização dos saberes e fazeres cotidianos como princípios para tais processos. São exemplos desse tipo de ação: as redes e coletivos docentes na América Latina, as Expedições Pedagógicas na Colômbia, México, Argentina e Bolívia (DUHALDE, 2012) e os encontros e fóruns entre e com docentes, como o Fórum de Alfabetização, Leitura e Escrita (FALE4), nos estados do Rio de Janeiro (UNIRIO e UERJ/FFP) e São Paulo (UNICAMP) (SAMPAIO; RIBEIRO; MORAIS, 2014).

Apesar desses movimentos cada vez mais mobilizarem docentes e educadores a compartilharem suas práticas e saberes e narrarem suas experiências com os outros, num movimento de partilha e retroalimentação, no que se refere às políticas públicas para formação em marcha no Brasil e na América Latina, sobretudo agora em tempos de retrocessos e ataques à educação pública e popular, a tônica parece recair sobre a ideia de capacitação, iluminação dos professores. Em diferentes países de nossa América Latina, distintos programas e

\footnotetext{
${ }^{4}$ O Fórum de Alfabetização, Leitura e Escrita (FALE) nasceu em 2007, como ação de pesquisa, ensino e extensão no bojo de um projeto coordenado pela professora Carmen Sanches Sampaio, na Universidade Federal do Estado do Rio de Janeiro (UNIRIO). O FALE/ UNIRIO aconteceu durante sete anos, entre 2007 e 2013. Desde 2009, o FALE foi ampliado em parceria com outros grupos e instituições. Até a presente data, acontece em São Gonçalo (UERJ/FFP), sob a coordenação das professoras Jacqueline de Fátima dos Santos Morais e Mairce Araújo, e em Campinas (UNICAMP), sob a coordenação do professor Guilherme do Val Toledo Prado. Além desses espaços, o FALE também ocorreu nas cidades de Três Rios e Angra dos Reis, ambas no estado do Rio de Janeiro, fruto de parceria entre as respectivas Secretarias Municipais de Educação e a UNIRIO. O Fórum tem como princípio o diálogo e a partilha de saberes e experiências entre a universidade e a escola básica, de modo a fazer circular conhecimentos produzidos no contexto da prática cotidiana e a investir em um processo outro de formação docente, no qual professores e professoras se assumam como autores e sujeitos de suas formações.
} 
infância, alteridade e formação docente: encontro com as crianças como potência de transformação

ações visam "preparar" o professor, suprindo supostas carências a ele atribuídas. Por vezes, chega-se ao ponto de negar os saberes docentes e indagar sua "aptidão" para dar aula, como está ocorrendo no Brasil, no bojo da Reforma do Ensino Médio realizada pela presidência da República, com o presidente ilegítimo Michel Temer: sem discussão com a sociedade nem com educadores e pesquisadores da área, a proposta põe em questão a "capacidade" dos professores para darem aula e abre possibilidade para a atuação de pessoas "com notório saber".

Nesse cenário, aos professores reserva-se, se levamos em consideração grande parte das ações e práticas de Secretarias Municipais e Estaduais de Educação Brasil afora, propostas de "atualização" ou "capacitação". Essas palavras atribuídas a esse processo não são à toa: elas dão a ver uma concepção de formação que esvazia o sujeito de sua capacidade reflexiva, autoral, produtora de conhecimento e saber pedagógico. Ora, só se atualiza ou capacita quem é, aprioristicamente, compreendido como desatualizado ou incapaz!

Nessa perspectiva, a concepção de ensinoaprendizagem que está em cena é a de que bastaria "fornecer" ao professor novos artefatos teóricos que, desse modo equipado, ele estaria apto a exercer uma docência "qualificada". Concepção que indica um entendimento de conhecimento como saber acumulado e vindo de fora, na contramão do sentido de auto-construção que caracteriza, ao nosso ver, o processo de (auto)formação docente.

Obviamente, tais propostas não refletem a totalidade das políticas para a área. Há outras ações que buscam investir na formação docente a partir de outros vieses, apostando na arte, na literatura, na pesquisa, na reflexão coletiva e na partilha de saberes e experiências como potencialidade para o processo formativo docente, como os cursos de Pós-graduação lato sensu e extensão em Educação Infantil, oferecidos então pelo Ministério da Educação através de instituições federais para profissionais já atuantes na área ${ }^{5}$. Todavia, vale ressaltar que a nova

\footnotetext{
${ }^{5}$ A Política Nacional de Formação de Profissionais do Magistério da Educação Básica, criada em 2009 pelo Decreto $\mathrm{n}^{0}$ 6.775, expressava a preocupação com a formação docente de professores, tendo como objetivo apoiar, em regime de colaboração entre a União, os Estados, o Distrito Federal e os Municípios, a formação inicial e continuada de docentes das redes públicas. O projeto de Cursos de Especialização em Docência na Educação Infantil lançado em 2009 contou com a
} 
(?) política de formação assumida pelo MEC, que defende o "notório saber" em detrimento da formação, já pôs fim à oferta desses cursos. A partir deste ano de 2017 não haverá, ao que tudo indica, abertura de novas turmas dos cursos de Pósgraduação e extensão em Educação Infantil.

Compete salientar que tal política de desmonte e descontinuidade não é tão nova assim. Ela faz parte de uma agenda neoliberal da educação que, de alguma maneira, vem sendo cumprida, com mais ou menos intensidade, por governos de direita e/ou esquerda. Parece que, em matéria de educação, ao se pensar em América Latina, a única via pensada como viável tem sido a neoliberal (ANDERSON, no prelo). Quiçá, essa postura atende ao discurso de privatização da educação pública, vendendo a imagem da escola como "incapaz de ensinar" e da universidade como "ineficiente em formar", ideias que ganham força e se consolidam no meio social mais amplo, fragilizando o reconhecimento da educação pela opinião pública. Daí que se justificam os investimentos na iniciativa privada, através da realização de contratos milionários com organizações não governamentais, seja para aquisição de "materiais didáticos" (cartilhas e apostilas, por exemplo), seja para a oferta de "formação" (propostas pontuais de cursos ou "capacitações aligeiradas"). Precarizam-se algumas escolas, muitas escolas, e, a partir dessas produções, generaliza-se, dizendo ser esse o retrato da educação.

No entanto, compreendemos que não é bem assim. Defendemos serem os professores sujeitos de conhecimento, produtores de saberes e ativos em seu próprio processo formativo. Corroboramos com a ideia do professor como profissional reflexivo (PÉREZ GOMEZ, 1992). Inclusive, compreendemos que a relação de dominação do intelectual/pesquisador identificado com a epistemologia moderna sobre os oprimidos/professores não se dá com passividade, pelo menos não quando se passa a ver um pouco abaixo das aparências. Os docentes fazem usos (CERTEAU, 2012) outros dos materiais

participação de 33 instituições de ensino superior. A implementação desses cursos estava inserida no âmbito da Política Nacional de Formação de Professores para a Educação Infantil, sob a responsabilidade da Secretaria de Educação Básica (SEB), do Ministério da Educação (MEC), em parceria com as instituições federais de ensino superior e as Secretarias Municipais de Educação, tendo como princípio a troca de experiências e a construção coletiva. 
pedagógicos que recebem, assim como das "capacitações" e "atualizações" ofertadas. Usos fora das expectativas, fora do esperado, desobedecendo o determinado nas suas práticas cotidianas de sala de aula. Revela-se, assim, a inventividade dos professores, "[...] dos quais se esconde sob o pudico nome de consumidores, o estatuto de dominados (o que não quer dizer passivos ou dóceis). O cotidiano se inventa com mil maneiras de caça não autorizada" (Idem, p. 38).

É nessa cotidianidade da escola que muitos sujeitos vão driblando, buscando outros caminhos, que fingem aceitar a relação de dominação da ciência moderna como "a forma de conhecimento hegemônico tanto no sistema educacional como fora dele" (SANTOS, 2009, p. 27). Esse obedecer desobedecendo fica claro na fala da professora Carla Bronzeado, como discutem Sampaio e Ribeiro (2014), trazendo a narrativa produzida pela docente em um dos encontros do Fórum de Alfabetização, Leitura e Escrita ocorrido na UNIRIO, ao se referir ao material imposto às professoras alfabetizadoras pela Secretaria Municipal de Educação à época:

- Eu faço [a apostila], mas faço só um pouquinho. Na maioria do tempo, faço o que acredito com as crianças.

Esse mesmo movimento é também plasmado pela professora Ana Paula Calmon, em diálogo com estudantes de graduação a respeito de suas práticas alfabetizadoras:

-Eu dou os cadernos de atividades da prefeitura para as crianças levarem para casa e fazerem nas férias, como atividade opcional.

Sim, o professor é esse sujeito que dobra o instituído; complexifica a prática no isso, no aquilo e no contrário de tudo, fugindo muitas vezes às rotulações e simplificações do seu fazer. No encontro e diálogo com seus pares, potencializa-se no se tornar um professor outro no exercício da docência e a indagar suas certezas, pontos de vista e verdades. Mas, são só os seus pares docentes que ocupam esse lugar alteritário, o qual possibilita uma (tans)formação constante? Qual o papel da criança na formação do professor? O que ensina quem aprende? O que lhes ensinam crianças pequenas com as quais atuam professores e professoras cotidianamente? 
Este texto se debruça sobre estas questões, buscando tecer reflexões sobre o papel/ importância das crianças no processo de deslocamentos (trans)formativos do professor e da professora. Para tal, lança mão de experiências vividas no cotidiano escolar, recolhidas por meio do mergulho no cotidiano (ALVES, 2008), potencializado pela pesquisa com os cotidianos escolares (GARCIA, 2003; OLIVEIRA; ALVES, 2008). Utilizamos, neste sentido, procedimentos e instrumentos metodológicos como o caderno de campo, a gravação de áudio, a fotografia e a conversa. Para este texto, selecionamos duas cenas vividas no cotidiano de uma escola pública na zona norte da cidade do Rio de Janeiro, as quais nos ajudam a pensar a respeito do tema aqui em discussão.

Interessa-nos, pois, no diálogo com essas experiências, pôr em discussão concepções de formação e de criança, defendendo esta última como um outro legítimo (e potente!) na formação do professor. Além disso, convidar a pensar a formação com a infância na qualidade de uma formação como experiência: aquela que dá a pensar e a pensar-se, uma formação que nos desloca e provoca a indagar nossas certezas e verdades cristalizadas.

\section{cenas do cotidiano escolar: a criança e o deslocamento (trans)formativo docente}

Bernardo é quase árvore. Silêncio dele é tão alto que os passarinhos ouvem de longe.

E vêm pousar em seu ombro.

Seu olho renova as tardes.

Guarda num velho baú seus instrumentos de trabalho:

um abridor de amanhecer um prego que farfalha um encolhedor de rios - e um esticador de horizontes.

(Bernardo consegue esticar o horizonte usando

Três fios de teias de aranha. A coisa fica bem Esticada.). Bernardo desregula a natureza; Seu olho aumenta o Poente. (Pode um homem enriquecer a natureza com a sua incompletude?)

(Manoel de Barros)

Na literatura pedagógica não é estranha a afirmativa de que o professor não se forma sozinho, mas com o outro, com seus pares. Parece quase inelutável, nas 
atuais pesquisas no campo da formação docente ${ }^{6}$, a assertiva de que a formação não é um processo solitário, autocentrado, e, sim, alteritário, compartilhado (SOUZA, 2006; SÜSSEKIND; GARCIA, 2011). No entanto, compete perguntar: é a criança um outro da/ na formação docente? Pode a criança ser um sujeito partícipe da formação do professor e da professora? Em que medida? Como? Por quê?

Ao compreendermos a criança como sujeito de conhecimento, um outro legítimo produtor de saberes e cultura (MELLO, 2009), não como um sujeito da falta, um ainda-não, uma miniatura de adulto a ser alguém um dia, e sim como um sujeito hoje, em toda sua potência afirmativa, um devir que dobra a lógica adultocêntrica e faz do tempo cronológico uma coisa outra, tomada pela intensidade e pela experiência (KOHAN, 2007), acreditamos que ela, sim, pode tornar possíveis movimentos de deslocamentos docentes.

Com a ideia de movimentos de deslocamentos docentes nos referimos ao exercício do estranhamento, da indagação de si mesmo, da problematização do próprio fazer docente, da impossibilidade de se manter exatamente tal qual se era antes do encontro/ confronto com o outro, essa alteridade que me provoca, que me afronta com o que/ quem não sou eu, mas que também me forma, me põe em questão, desbota meus limites e mapas cognitivos.

Sim, e a criança é, também, esta alteridade que nos choca, nos provoca, nos desafia, nos ensina, nos toca, nos afasta, nos aproxima. Como dizia o poeta, no entanto, não basta ter olhos para ver. Para que isso ocorra, para a criança poder colocar em xeque as certezas docentes com suas palavras e contrapalavras, esticando horizontes com teias de aranha como nos diz Manoel de Barros, na epígrafe desta parte do texto, por meio de suas lógicas e pensares tão singulares, de provocar o professor a pensar e a pensar-se, este precisa estar aberto, compreender-se sujeito inacabado, entender que "para combater a verdade do poder é necessário colocar em dúvida o poder da verdade" (LARROSA, 2010, p. 163). Portanto, sendo a formação um processo alteritário, mas também

\footnotetext{
${ }^{6}$ A esse respeito, ver GT 8 - Formação de Professores - da Anped.
} 
autoproduzido, singular, há que se mover o pensar, desbotar as zonas limítrofes de nossas compreensões e entender que a verdade, nossa verdade - crenças, certezas, modos de fazer - estão sendo tais como são, mas podem ser diferentes.

Nesse sentido, trazemos duas cenas do cotidiano escolar vividas por um professor iniciante recém-formado, com crianças entre 6 e 7 anos de idade, em um segundo ano de escolaridade dos Anos Iniciais do Ensino Fundamental. Pensamos que tais cenas nos dão elementos para refletir sobre a discussão aqui proposta.

cena 1

Era dia 18 de julho de 2013. Eu estava sentado na roda com as crianças enquanto a outra professora com quem compartilho a turma alguns dias da semana estava colando bilhetes nas agendas. Eu explicava a atividade proposta para o período de recesso: cada criança escolheria um livro dentre os que apresentei e o levaria para casa para ler durante o recesso. Após a leitura, recontaria a história por escrito, podendo ilustrá-la, para, na volta do recesso, fazermos nossa roda do projeto "Lá vem história" com as crianças lendo e contando a história que leram.

Lembro que falei por uns minutos e, logo em seguida, perguntei se alguém ainda tinha dúvida. Gabriel e Victor levantaram a mão. Então eu disse à turma que explicaria novamente, pois ainda havia colegas com dúvidas. Nesse momento, Lucas Dias comenta:

- Tá, tio! Mas fala na nossa língua, tá?

Emudeci. As palavras do menino me fizeram pensar um milhão de coisas em poucos segundos. Da mesa, a professora olhou para mim. Entreolhando-nos, rimos. Então eu disse:

- Hoje ele me ensinou!

- Só a você não! A mim também! - respondeu ela.

- Lucas, vou tentar falar na lingua de vocês. - respondi.

Expliquei novamente a proposta, tentando ser o mais claro e objetivo possível. Só neste momento me dei conta de que tinha usado, na primeira vez, palavras como "transcrever" e "autoria", além de outras provavelmente desconhecidas ou estranhas para as crianças. Desta vez, falei de outro modo. Ao final, perguntei se agora tinha sido claro. Algumas crianças responderam:

- Agora sim! Agora foi na nossa lingua!

(Caderno de campo do professor. 19/07/2013)

cena 2

Era uma terça-feira de junho cuja data exata não consigo recuperar. Eu pedira para as crianças fazerem uma pesquisa sobre seus bairros na sexta-feira anterior e na segundafeira não tinha havido aula. Cada um falou o bairro onde mora e eu anotava no quadro. Após esse movimento, sorteei e chamei cada criança para encontrar e marcar seu bairro no mapa da cidade do Rio de Janeiro. Foi uma festa! Elas ficaram contentes e queriam ajudar umas às outras. Fizemos esse movimento. Após esse momento, pedi que sentassem nos seus lugares para copiar os 17 nomes de bairros (as crianças 
moravam em 17 bairros diferentes, pois alguns se repetiam entre os mais de 20 alunos). Listei-os no quadro e pedi que começassem.

Alguns minutos depois, Rafael da Silva, um menino que ainda precisa de mais ajuda para escrever, embora copie do quadro sozinho, foi até onde eu estava, com o caderno na mão, e me disse:

- Tio, tô cansado! Não quero copiar mais isso não.

Eu insisti que copiasse, mas ele resistiu. Então falei:

- Olha, todos os seus amigos estão copiando... Por que você não vai copiar? Só você não vai ter o nome do bairro de todo mundo no caderno?

- Mas eu não quero... - ele retrucou.

- Mas é importante, Rafa. - insisti ainda.

- Mas para que eu tenho de copiar isso?

Diante daquela pergunta, muitas das discussões vividas na universidade e no grupo de pesquisa do qual faço parte desde 2009 vieram à minha cabeça. Então eu, que há muito venho me desafiando a pensar, com meus pares, a possibilidade de uma alfabetização outra, reforçava a mera cópia? E o pior: não percebia que o fazia? Naquele momento, com a fala daquele menino, consegui perceber o que não podia sozinho. Rafael me abriu os olhos para a incoerência entre o que propunha como atividade e a concepção de alfabetização que venho me desafiando a viver e defendo. Respirei fundo e respondi:

- Boa pergunta. Eu também não sei por que você tem de copiar o nome desses bairros todos... Você me fez uma pergunta difícil.

- Então eu não preciso copiar?

Sorri, sem saber o que responder de verdade. Ele entendeu. Pegou uma folha em branco e foi desenhar.

(Caderno de campo do professor. 25/06/2013)

Embora as narrativas do professor falem por si, dispensando explicações de qualquer sorte, achamos importante e potente pensarmos com elas. A primeira impressão que nos toma é o quão as crianças podem deslocar a(s) lógica(s) adultas, o quão são capazes de pensar ao revés, de provocar o pensamento, de interromper e mudar o curso do acontecimento. Desnaturalizam o que se repete pela força do hábito. Trazem um olhar inusitado para o comum e ordinário - esticam horizontes, como nos diz Manoel de Barros. Forçam o pensar de um modo simples e belo, levando-nos a compreender que uma formação com a infância, tendo a criança como um outro, é uma formação que tem no riso um elemento constitutivo e forte. Se voltarmos às duas narrativas, percebemos que o professor se remeteu ao riso e/ou ao sorrir em cada uma delas. Isto não é à toa, pois:

O riso destrói as certezas. E principalmente aquela certeza que constitui a consciência enclausurada: a certeza de si. Mas só na perda da certeza, no permanente questionamento da certeza, na distância irônica da certeza, está a possibilidade do devir. O riso permite que o espírito alce voo sobre si mesmo (LARROSA, 2010, p. 181). 
Sim, as crianças nos convidam ao riso. E esse convite nos provoca à transformação numa direção desconhecida, incontrolável, pois o devir é isto: tornar-se sempre outro de si mesmo, sem saber bem aonde esse movimento de (trans)formação e deslocamento vai nos levar. O riso tem caráter transgressor, mobilizador da crítica ao poder estabelecido. Surge muitas vezes como uma brecha, um intervalo em que o controle "abre um respiro" nas nossas tão humanas falhas e equívocos. A presença do riso traz uma leveza e ludicidade ao discurso, cria uma abertura para o que não se tem certeza, território instável para o surgimento de um outro modo de ver o contexto e a si próprio. Para Alberti (1999), ele, o riso, refina nossos discursos poéticos.

Quiçá, um formar-se com a infância é localizar-se neste espaço onde o riso se faz possível, é mover-se, abandonar a inércia fundante do pensamento cristalizado, da verdade cimentada, abrir-se à escuta, porque a criança é um outro que escapole, se mexe, escorrega, não se deixando sumariar e/ou apreender (RIBEIRO; RODRIGUES, 2015); um sujeito que tem muito a dizer, a nos dizer, com seus gestos, palavras e, às vezes, silêncios.

A este movimento potencializado pelas crianças, pelo encontro/diálogo com elas, a esta formação com a infância estamos chamando de formação como experiência, pois nos sacode, desloca, às vezes incomoda e emudece, mas, ao passarmos pelo desconforto, pelo emudecimento e pela desaprendizagem, podemos percebermo-nos outros, rir. Todavia, insistimos: para viver tal processo, havemos de estar abertos ou nos abrir para ele, pois, como nos provoca Larrosa (2011), o sujeito da experiência é o sujeito ex-posto, aberto, e não o sujeito fechado em suas verdades, irredutível em suas certezas. Sem abertura não há conversa, nem encontro, nem movimento.

Com as crianças e seus sinais e provocações, podemos perceber que nossas práticas, assim como quaisquer outras, abrigam o isso e o aquilo outro, com ênfase no " $\mathrm{e}$ ". Pensar a ligação que o " $\mathrm{e}$ ” produz nos faz descartar a alternância e pensar a prática como múltipla, como espaçotempo da concomitância. Nosso desafio, pois, é aprender a ser "melhores" professores - ou professores outros - com as crianças. 
E aqui, talvez, more o sentido de "dodiscência", ideia proposta por Freire: quem ensina aprende, e quem aprende ensina.

Inundados, então, nessa dialogia que produz um atravessamento violento, nós, professores e professoras, somos provocados a todo o tempo e o tempo todo a conhecer um pouco mais e a tentar viver um processo pedagógico com as crianças que produza sentidos - para elas e para nós - baseados nas relações alteritárias. Somos excitados a vivenciar o educar enquanto encontro/diálogo/confronto com o outro:

Não há educação fora da relação entre o eu e o outro. E tal como em Bakhtin, desta relação com a alteridade nenhum dos dois sai inalterado, ninguém sai como entrou. Se no mundo da vida não saímos de um diálogo sem com ele nos enriquecermos, também nos processos educativos professor e aluno saem diferentes, porque nessa relação ambos aprendem (GERALDI, 2013, p. 13).

Essa relação de reciprocidade joga para longe o cânone colonial/moderno de conhecimento, já que se encontra fora da concepção de racionalidade do mesmo. Não se trata mais de "capacitar", "reciclar" ou "atualizar". Trata-se, aqui, de uma formação de professores situada no campo do sentir, do experienciar, do se constituir com o outro, neste caso, a criança.

Sim: o professor e a professora se formam com a criança. Não é só ela, a criança, que precisa da mediação, da figura de outro sujeito para instigá-la, desafiá-la a pensar, não é apenas ela que tem sua zona de desenvolvimento proximal (VIGOSTKI, 2013). O adulto professor também tem a sua, e a criança pode atuar nela, com suas palavras, suas falas inesperadas, suas provocações (in)tempestivas. Com ajuda, inclusive a das crianças, nós, professores e professoras, podemos hoje nos sentir provocados a fazer e perceber com ajuda o que amanhã faremos, perceberemos e, por que não, compreenderemos sozinhos. Esta é mais uma riqueza da formação com a infância: somos impelidos a buscar espaços formativos outros, a conversar com nossos pares, a estar sempre estudando, procurando ajuda. Seres perfectíveis que somos, inacabados e também em processo de formação permanente.

Compreendemos assim que a formação não é algo que se recebe, mas se faz num processo ativo que requer envolvimento, a aproximação e o encontro com 
outros. Formar-se é, portanto, constituir-se num processo, implicar-se nele; um auto e alter transformar-se ininterrupto. Com isso, queremos dizer que a formação se dá nas relações com pessoas, livros, filmes, experiências, lugares... Nossa formação é um processo singular, único, por isso essa dimensão de auto-ria; e também é atravessada pelo outro, por isso um processo alteritário.

Tal modo de pensar a formação de professores demanda a assunção de um marco outro de concepção de produção de conhecimento e, consequentemente, a opção por uma estética outra. Isto porque a estética do conhecimento hegemônica, moderna, está relacionada a um representacionalismo no qual quem representa julga-se capaz de fazê-lo imparcialmente, como um pintor que acredita criar uma obra capaz de capturar a realidade (estática) de maneira fidedigna, mas sem pintar-se, mesmo que da maneira mais sutil em sua obra; sem imprimir nela sua subjetividade.

Tal estética, ao negar a presença, a própria vida, tenta impedir um conhecimento sensível, um conhecimento que tenha como centralidade a experiência, a intimidade, o riso. E é justamente pela liberdade e autenticidade, as quais a estética representacionalista moderna tenta apagar, que uma formação com a infância, como experiência, nos provoca. Está-se em questão uma estética que admite “[...] en su seno el tiempo, el cambio, la transformación, porque el punto de partida es el de la dinamica vincular y no el de las esencias absolutas del dualismo o el monismo proprios de nuestra tradición occidental" 7 (NAJMANOVICH, 2008, p. 20).

Trata-se de uma estética outra, de uma práxis vital e uma ética que levam a criar e habitar novos espaçostempos existenciais, a experimentar o mundo de novas formas, de construí-lo compartilhadamente, nas interações e a partir de indagações. Isso aprendemos com as crianças deslocando-nos e (trans)formandonos, isto é, vivendo a possibilidade de nos tornamos outros de nós mesmos, fazermo-nos diferentes, poder pensar outras coisas, descobrir possibilidades

\footnotetext{
7 "[...] em seu seio o tempo, a mudança, a transformação, porque o ponto de partida é o da dinâmica vincular e não o das essências absolutas do dualismo ou o monismo próprios de nossa tradição ocidental". (Tradução nossa).
} 
outras de ser e estar professor. Assim, o estar com a infância, o abrir-se a ela, escutando o que as crianças têm a nos dizer e a ensinar pode fazer aflorar processos (trans)formativos docentes, tendo no riso, na experiência e na reflexão ingredientes constitutivos da formação.

Se é verdade que só com a ajuda do outro podemos falar na primeira pessoa, com as próprias palavras e ideias, porque é na relação com ele que nos conhecemos um pouco mais, mas nunca completamente, também é verdade que a criança é, sim, um outro, um legítimo outro (MATURANA, 1998). E, enquanto tal, ela nos abre, insistimos, a possibilidade de tornarmo-nos outros em relação a nós mesmos, como profissionais e como pessoas. Nesse conhecer-se um pouco mais, chegamos ao novo mundo que somos, mas sendo sempre de passagem, indo em direção ao próximo que as relações alteritárias e empáticas nos impelem. Compreender a formação neste viés e reconhecer a criança como outro da/na formação nos deixa, pois, um convite e uma provocação.

\section{conclusão? inflexão: palavras-convite para seguir pensando}

Como um ponto de inflexão, este encerramento de texto nos impele ao início, retornando algumas perguntas: Qual o papel da criança na formação do professor? O que ensina quem aprende? O que ensinam aos docentes as crianças pequenas com as quais atuam estes professores e professoras cotidianamente?

Em vez de buscar respostas definitivas às perguntas, achamos importante deixá-las pulsar, forçar a pensamento, lampejando reflexões provisórias e cintilando, sempre, outras possibilidades de entendimento. O que elas abrem como possibilidade de compreensão no tocante à formação docente? Deslocam a formação do lugar de "capacitação", "atualização" ou "reciclagem"? Quando o sujeito aprendente é encarado também como sujeito ensinante, e o sujeito ensinante é encarado também como sujeito aprendente, o que muda?

Seguir pensando estas questões, nos parece, torna possível o fortalecimento da luta e da assunção do lugar ético, estético e político por uma formação docente como experiência, a qual não subjugue esses sujeitos, reservando-lhes um lugar inferior, silenciado. Compele-nos, também, a assumirmo-nos, como professores e 
professoras, como autores de nossas falas e pensamento e, portanto, de nossa formação, um processo que deflagra a possibilidade de vivê-lo também com as crianças!

Ao compreender que só podemos assumir nossa autoria à medida que reconhecemos a do outro, coloca-se como pressuposto das relações pedagógicas a cidadania, como algo praticável no dia a dia e não como algo a ser alcançado no futuro. Isso implica que a criança seja, claro, compreendida também como sujeito autor, tenha legitimada sua voz, seu ponto de vista. Daí que uma formação com a infância não pode ser outra coisa senão uma formação inventiva, alegre, viva, risonha e risível, isto porque "uma capacidade que pensa e dá o que pensar, isso também é a infância" (KOHAN, 2007, p. 131).

Mas, são palavras-convite para seguirmos pensando e, sobretudo, aprendendo com as crianças...

\section{referências}

ALBERTI, Verena. O riso e o risível na história do pensamento. Rio de Janeiro: Jorge Zahar/Fundação Getúlio Vargas, 1999.

ALVES, Nilda. Decifrando o pergaminho - o cotidiano das escolas nas lógicas das redes cotidianas. In: OLIVEIRA, I. B.; ALVES, N. (orgs.). Pesquisa nos/dos/com os cotidianos das escolas: sobre redes de saberes. 3. ed. Rio de Janeiro: DP\&A, 2008.

ANDERSON, Gary. O potencial democrático da pesquisa-ação participativa (PAR): resistindo ao neoliberalismo e à Nova Gestão Pública em escolas e universidades. In: RIBEIRO, Tiago; SOUZA, Rafael de; SAMPAIO, Carmen Sanches. Conversa como metodologia de pesquisa: por que não? No prelo.

CERTEAU, Michel de. A Invenção do Cotidiano: Artes de fazer. 13. ed. Petrópolis: Vozes, 2012.

DUHALDE, M. A. Las redes de educadores/as que hacen investigación en el devenir del Movimiento Pedagógico Latinoamericano. In: Encuentro Internacional de Pedagogías de Emancipación y Resistencia al Neoliberalismo. Seminario de la Red-SEPA, Vancouver, Canadá, 2012.

GARCIA, Regina Leite. (org.) Método: pesquisa com o cotidiano. Rio de Janeiro: DP\&A, 2003.

GERALDI, João Wanderley. Bakhtin tudo ou nada diz aos educadores: os educadores podem dizer muito com Bakhtin. In: FREITAS, Maria Teresa de Assunção (Org.).

Educação, arte e vida em Bakhtin. Belo Horizonte: Autêntica, 2013.

KOHAN, Walter Omar. Infância, estrangeiridade e ignorância: ensaios de Filosofia e Educação. Belo Horizonte: Autêntica, 2007.

LARROSA, Jorge. Pedagogia Profana: danças, piruetas e mascaradas. Belo Horizonte:

Autêntica, 2010.

LARROSA, Jorge. Experiência e alteridade em educação. Revista Reflexão e Ação, Santa Cruz do Sul, v.19, n. 2, p.04-27, jul./ dez. 2011. 
MATURANA, H. Emoções e linguagem na educação e na política. Belo Horizonte: UFMG, 1998.

MELLO, Marisol Barenco. Lógicas Infantis: é a criança um outro? In: LOPES, Jader Janer Moreira; MELLO, Marisol Barenco. "O jeito de que nós crianças pensamos sobre certas coisas": Dialogando com lógicas infantis. Rio de Janeiro: Rovelle, 2009.

NAJMANOVICH, Denise. Mirar con nuevos ojos: nuevos paradigmas en la ciencia y pensamento complejo. Buenos Aires: Biblos, 2008.

OLIVEIRA, Inês Barbosa; ALVES, Nilda (orgs.). Pesquisa nos/dos/com os cotidianos das escolas: sobre redes de saberes. 3. ed. Rio de Janeiro: DP\&A, 2008.

RIBEIRO, T.; RODRIGUES, A. Infância em Portinari: potencialidades para pensar uma escola em Devir. Revista Interinstitucional Artes de Educar. Rio de Janeiro, v. 1, n. 1, p. 49-65, fev./ maio, 2015.

SAMPAIO, Carmen Sanches; RIBEIRO, Tiago. Velhas perguntas, atuais questões: inquietudes e convites para pensar a formação da professora alfabetizadora. Atos de Pesquisa em Educação. v. 9, n. 1, jan./abr. 2014.

SAMPAIO, Carmen Sanches; RIBEIRO, Tiago; MORAIS, Jacqueline de F. dos Santos. Formação docente instituinte: o Fórum de Alfabetização, Leitura e Escrita. Revista Aleph. V. 11, n. 22, jul./ dez. 2014.

SANTOS, Boaventura de Sousa. Para uma pedagogia do conflito. In: SANTOS, Boaventura de Sousa. Contra o desperdício da Experiência. Porto Alegre: Redes editora, 2009. SOUZA, Elizeu Clementino de. O conhecimento de si: estágio e narrativas de formação de professores. Rio de Janeiro: DP\&A; Salvador: UNEB, 2006.

SÜSSEKIND, M.L.; GARCIA, A. (org.) Diálogo e formação de professores: UniversidadeEscola. Petrópolis, RJ. De Petrus Et Alli; Rio de Janeiro: FAPERJ, 2011.

VIGOTSKI, L. S. A formação social da mente. São Paulo: Martins Fontes, 2013.

recebido em: 12.10 .2017

aprovado em: 30.01 .2018 